\title{
Tuberculosis screening in asylum seekers in Germany, 2015: characteristics of cases and yield
}

\author{
To the Editor:
}

In 2015, according to the International Organization for Migration (IOM), 244 million people worldwide were international migrants, representing the highest number ever recorded [1]. The level of forced displacement globally was the highest since World War II, with a dramatic increase in the number of refugees, asylum seekers and internally displaced people. Germany became one of the largest recipients of first asylum seeking claims [2].

To improve tuberculosis (TB) prevention and care for migrants, systematic screening is regarded as a potential strategic measure. However, there is ongoing discussion regarding the most appropriate approach (pre-entry versus post-entry) and screening tools. It remains to be decided how to best target screening based on TB risk, e.g. by considering screening yields or TB rates in the countries of origin [3-8].

Germany is a low TB incidence country, with a notification rate of 7.3 cases per 100000 population and a prevalence of $5865 \mathrm{~TB}$ cases in 2015. Immigrants to Germany largely originate from countries with markedly higher TB incidences. Accordingly, TB notification rates are about 20 times higher among foreign compared with German citizens [9]. Furthermore, the declining trend in TB incidence in Germany ended in 2013, largely associated with demographic changes caused by migration, and an increase in TB case numbers has been observed since then [10]. There is no general screening for TB in migrants to Germany; however, the German Protection Against Infection Act (Infektionsschutzgesetz, IfSG) stipulates that anyone who is to be accepted into a community facility for refugees or asylum seekers, or into an initial reception centre of the Federal Government for repatriates, must submit a medical certificate stating that they present no signs of infectious pulmonary TB [11]. The certificate for individuals aged 15 years or older must be based on a chest X-ray, with the exception of pregnant women, who are exempt from this requirement. For pregnant women and for children younger than 15 years of age, the medical certificate should be based on other findings that rule out infectious pulmonary TB [11]. To facilitate the implementation of this legal requirement, expert statements were developed in 2015 suggesting that lung $\mathrm{X}$-ray remains an appropriate screening approach for infectious pulmonary TB in adults [12]. For pregnant women and children younger than 15 years of age, initial immunodiagnostic tests such as tuberculin skin test (TST) or interferon-gamma release assay (IGRA) were recommended to identify any need for further investigation and treatment, in line with existing national recommendations [12-15].

Active TB disease (clinical case definition [16]) is a notifiable disease in Germany. The mode of case finding (reason for diagnosis) is part of the notified information; categories of the variable include diagnosis upon clinical presentation and diagnosis by post-mortem examination (both categorised under passive case finding $[\mathrm{PCF}]$ ), as well as contact tracing and screening at entry of shared accommodation for specified groups, including asylum seekers (both categorised under active case finding $[\mathrm{ACF}]$ ).

In the current study, we aimed to describe the demographic, epidemiological and clinical features of the cases of TB identified by screening among asylum seekers, and to estimate the screening yield in order to inform future screening policies.

We used German TB notification data for 2015, exported on March 1, 2016, and asylum seeker numbers for 2015 registered by the Federal Office for Migration and Refugees (Bundesamt für Migration und

@ERSpublications

TB screening among asylum seekers in Germany identified 1255 cases in 2015, and may have decreased TB exposure http://ow.ly/2d4n30f9w9b

Cite this article as: Fiebig L, Hauer B, Andrés M, et al. Tuberculosis screening in asylum seekers in Germany, 2015: characteristics of cases and yield. Eur Respir J 2017; 50: 1602550 [https://doi.org/10.1183/ 13993003.02550-2016]. 
Flüchtlinge (BAMF)) to establish case detection rates (point prevalence rates), as no countrywide data on the number of screened asylum seekers are available. Individual data were provided for the 12 most frequent countries of birth among screened asylum seekers with TB; all other countries were pooled. In the absence of published prevalence rates, we have cited estimated TB incidence rates (including HIV) by the World Health Organization (WHO) [17] to contextualise our case finding rates; however, it should be noted that direct comparison between incidence and point prevalence rates is inadequate.

In total, of 1255 notified TB cases were detected by ACF among asylum seekers, representing $21 \%$ of all notified TB cases in 2015. The most frequent countries of birth were the Syrian Arab Republic, Somalia, Eritrea and Afghanistan, followed by Pakistan, Kosovo, Gambia, Ethiopia, Iraq, Albania, Georgia and Serbia (the last three with the same number of cases; table 1). Patients born in Afghanistan, Somalia and Ethiopia were the youngest, and patients born in Georgia were the oldest (median age of 20 and 34 years, respectively; table 1). In total, 45 patients (3.6\%) were children younger than 15 years of age, and of these, 12 were born in the Syrian Arab Republic. The majority of patients were male. Approximately 13\% of patients had a history of previous TB; this proportion was highest for patients born in Georgia and Kosovo (37\% and 25\%, respectively). Among the TB patients identified by ACF, $89 \%$ had pulmonary TB, and of these, $7.6 \%$ had an additional extrapulmonary site of disease. For this, proportions were highest for patients born in Somalia and Gambia ( $18 \%$ and $14 \%$, respectively [data not shown]). Among the pulmonary TB cases, $59 \%$ were bacteriologically confirmed, with $26 \%$ being sputum smear positive and thus likely to be highly infectious. None of the other bacteriological investigations led to confirmation according to case definitions [16]. Multidrug-resistant (MDR) TB was found in 5.7\% of the 636 cases with drug-susceptibility testing results (table 1).

Compared with patients with TB identified by PCF from the same 12 countries of birth (data not shown), the patients with $\mathrm{TB}$ diagnosed by ACF were more often male (male:female ratio of 6.6 versus 3.0, respectively), were of a similar median age (24 years [interquartile range, IQR 19-32] versus 26 years [IQR 20-35], respectively) and were more often diagnosed with pulmonary TB (89\% versus $71 \%$, respectively), but were less likely to have sputum smear-positive TB (26\% versus $39 \%$, respectively). Length of stay in Germany and status of residency are unknown for the PCF group.

Case finding rates in 2015 based on notified TB cases among screened asylum seekers and registered asylum seekers in the respective year as denominator are as follows (per 100 000: 1210 for Somalia, 958 for Ethiopia, 622 for Gambia, 580 for Eritrea, 576 for Georgia, 331 for Pakistan, 152 for Serbia, 95 for Afghanistan, 62 for Kosovo, 45 for Albania, 37 for the Syrian Arab Republic and 27 for Iraq. These established case finding rates in Germany were, for the most part, many times greater than the WHO estimated TB incidence rates in the respective countries of birth [18]. This is especially the case for Eritrea and Serbia, whereas, the rates were lower for Afghanistan and Iraq (table 1).

Our analysis shows a considerable yield from the legally required TB screening among asylum seekers at entry of shared accommodation in Germany, as detected by case finding rates (e.g. individuals born/ originating from Ethiopia) and the absolute number of asylum seekers (e.g. Syrian Arab Republic) or both (e.g. Somalia and Eritrea).

Comparison with findings from other countries is hampered by different settings, screening policies, healthcare systems and the groups of migrants considered. Our findings are solely based on national TB notification data, which, in a complex and challenging situation as in 2015, may be subject to under-notification and can contain duplicates when individuals present in different places and use different names. Case ascertainment regarding ACF and PCF can vary when both presentation of TB-like symptoms and screening apply. However, the overall definitions for case reporting are standardised and well established since 2001. Given the decentralised implementation of screening in a federal republic such as Germany, no countrywide denominator, i.e. total number of people screened for TB, is available. Thus, the established TB rates by country of birth may only be considered as rough, conservative proxies for TB point prevalence rates in the respective groups.

In conclusion, screening activities for asylum seekers identified a considerable number of individuals with TB, of whom 291 had infectious sputum smear-positive pulmonary TB. Screening is likely to have decreased exposure to TB among vulnerable individuals, including children sharing the same, often crowded, accommodation. Early detection of infectious TB and isolation of patients also reduces the need for resource-intensive contact investigations at a later time. Even detecting bacteriologically negative TB by chest X-ray may help to reduce further TB transmission, given the risk for later progression to infectious TB [18].

The established variable, mode of case finding, in the notification dataset, with its categories including screening of specified groups, proved very useful for understanding changes in TB trend [10] and for 
TABLE 1 Demographic, epidemiological and clinical features of the tuberculosis (TB) patients notified in Germany in 2015, identified by screening and stratified by countries of birth

\begin{tabular}{|c|c|c|c|c|c|c|c|c|c|c|}
\hline \multirow[t]{2}{*}{ Country of birth } & \multirow[t]{2}{*}{$\begin{array}{c}\text { Cases } \\
\mathrm{n}\end{array}$} & \multirow[t]{2}{*}{$\begin{array}{l}\text { Median age } \\
\text { years (IQR) }\end{array}$} & \multirow{2}{*}{$\begin{array}{l}\text { Male: } \\
\text { female } \\
\text { ratio }\end{array}$} & \multirow[t]{2}{*}{$\begin{array}{l}\text { Previous TB } \\
\mathrm{n} / \mathrm{N}(\%)\end{array}$} & \multirow{2}{*}{$\begin{array}{c}\text { Presence of } \\
\text { pulmonary TB } \\
\mathrm{n} / \mathrm{N}(\%)\end{array}$} & \multicolumn{2}{|c|}{$\begin{array}{l}\text { Bacterial confirmation of } \\
\text { pulmonary TB } n(\%)\end{array}$} & \multirow{2}{*}{$\begin{array}{c}\text { MDR among } \\
\text { bacterially } \\
\text { confirmed TB with } \\
\text { DST } n / N(\%)\end{array}$} & \multirow{2}{*}{$\begin{array}{l}\text { Point prevalence } \\
\text { in Germany per } \\
100000(95 \% \mathrm{CI})\end{array}$} & \multirow{2}{*}{$\begin{array}{l}\text { WHO TB incidence } \\
\text { rates in countries } \\
\text { of birth }{ }^{\#} \text { per } \\
100000(95 \% \mathrm{CI})\end{array}$} \\
\hline & & & & & & Cult+ SSM- & Cult+ SSM+ & & & \\
\hline $\begin{array}{l}\text { Syrian Arab } \\
\text { Republic }\end{array}$ & 157 & $29(22-40)$ & 8.2 & 9/89 (10.1) & 146/157 (93.0) & 36 (24.7) & 37 (25.3) & $1 / 64(1.6)$ & $37(31-43)$ & 20 (15-25) \\
\hline Somalia & 155 & $20(17-25)$ & 5.5 & $5 / 82(6.1)$ & 126/154 (81.8) & 20 (15.9) & 45 (35.7) & $3 / 71(4.2)$ & $1210(1028-1414)$ & 274 (177-391) \\
\hline Eritrea & 148 & $23(20-27)$ & 6.7 & $4 / 85(4.7)$ & $124 / 148(83.8)$ & $31(25.0)$ & $58(46.8)$ & $2 / 93(2.2)$ & $580(491-681)$ & $65(30-113)$ \\
\hline Afghanistan & 146 & $20(17-27)$ & 5.3 & $8 / 76(10.5)$ & $130 / 145(89.7)$ & $38(29.2)$ & 41 (31.5) & $3 / 74(4.1)$ & $95(80-111)$ & 189 (122-270) \\
\hline Pakistan & 94 & $26(22-32)$ & 93.0 & $9 / 54(16.7)$ & $88 / 94$ (93.6) & 27 (30.7) & 28 (31.8) & $0 / 51(0.0)$ & 331 (268-405) & $270(175-386)$ \\
\hline Kosovo & 43 & 31 (22-38) & 2.1 & $8 / 32(25.0)$ & 41/43 (95.3) & $10(24.4)$ & $11(26.8)$ & $0 / 20(0.0)$ & $62(45-83)$ & Not available \\
\hline Gambia & 38 & $22(20-27)$ & All male & $1 / 24(4.2)$ & 28/38 (73.7) & $6(21.4)$ & $13(46.4)$ & $0 / 23(0.0)$ & $622(440-825)$ & 174 (131-223) \\
\hline Ethiopia & 33 & 20 (18-23) & 4.5 & $0 / 11(0.0)$ & 29/33 (87.9) & $7(24.1)$ & $13(44.8)$ & $0 / 19(0.0)$ & 958 (660-1342) & $192(142-250)$ \\
\hline Iraq & 33 & $25(20-30)$ & All male & $5 / 21(23.8)$ & $32 / 33$ (97.0) & 10 (31.3) & 10 (31.3) & $0 / 19(0.0)$ & 27 (19-38) & $43(38-49)$ \\
\hline Albania & 31 & $33(20-35)$ & 4.2 & $1 / 20(5.0)$ & $31 / 31(100.0)$ & $9(29.0)$ & 10 (32.3) & $0 / 16(0.0)$ & $45(30-63)$ & $19(16-22)$ \\
\hline Georgia & 31 & $34(30-40)$ & 14.5 & $7 / 19$ (36.8) & $31 / 31(100.0)$ & $16(51.6)$ & $5(16.1)$ & $9 / 18$ (50.0) & $576(392-816)$ & $99(80-120)$ \\
\hline Serbia & 31 & $32(25-49)$ & 1.6 & $3 / 22(13.6)$ & 29/31 (93.5) & 6 (20.7) & $12(41.4)$ & $0 / 14(0.0)$ & $152(103-216)$ & $21(19-24)$ \\
\hline Other & 254 & $29(23-37)$ & 7.4 & $33 / 166(19.9)$ & $232 / 253$ (91.7) & $62(26.7)$ & $70(30.2)$ & $16 / 127(12.6)$ & & \\
\hline Germany & 4 & 26.5 (19-38) & 3.0 & $0 / 4(0.0)$ & $4 / 4(100.0)$ & $1(25.0)$ & $1(25.0)$ & $0 / 2(0.0)$ & & \\
\hline No data & 57 & $27(21-35)$ & 5.3 & 2/31 (6.5) & 47/57 (82.5) & 12 (25.5) & $9(19.1)$ & $2 / 25(8.0)$ & & \\
\hline Subtotal (top 12) & 940 & $24(19-32)$ & 6.6 & $60 / 535$ (11.2) & $835 / 938(89.0)$ & $216(25.9)$ & 283 (33.9) & 18/482 (3.7) & & \\
\hline Total & 1255 & $25(20-33)$ & 6.6 & $95 / 736$ (12.9) & $\begin{array}{c}1118 / 1252 \\
\text { (89.3) }\end{array}$ & $291(26.0)$ & 363 (32.5) & $36 / 636(5.7)$ & & \\
\hline
\end{tabular}

IQR: interquartile range; Cult: bacteriological culture; SSM: sputum smear microscopy; MDR: multidrug resistance; DST: drug susceptibility testing; WHO: World Health Organization. : estimated by WHO [18], and including HIV. 
describing key features of TB among asylum seekers. Until strong evidence for any alternative or more targeted approach becomes available, the screening as currently performed appears reasonable, and it is important for rapid case detection and treatment, as well as for minimising TB transmission in Germany.

Lena Fiebig, Barbara Hauer, Marta Andrés and Walter Haas

Dept for Infectious Disease Epidemiology, Robert Koch Institute, Berlin, Germany.

Correspondence: Lena Fiebig, Dept for Infectious Disease Epidemiology, Robert Koch Institute, Respiratory Infections Unit, Seestr. 10, 13353 Berlin, Germany. E-mail: fiebigl@rki.de

Received: Dec 282016 | Accepted after revision: Aug 022017

Conflict of interest: None declared.

Acknowledgements: We thank everyone who contributed to the screening, case management and TB surveillance and control in Germany. We also thank Doris Altmann (Robert Koch Institute, Berlin, Germany) for data preparation, Bonita Brodhun (Robert Koch Institute) for the management of TB notification data, Nita Perumal (Robert Koch Institute) for helpful comments on the manuscript, and Harald Lederer (Bundesamt für Migration und Flüchtlinge) for providing the numbers of registered asylum seekers.

Author contributions were as follows. Lena Fiebig, Barbara Hauer and Walter Haas conceptualised the study. Lena Fiebig drafted the manuscript and performed the data analysis. Barbara Hauer performed the literature review. Marta Andrés helped in the data analysis. Barbara Ha, Marta Andrés and Walter Haas collaborated in writing the manuscript. All authors reviewed and approved the final manuscript.

\section{References}

1 International Organization for Migration. Global Migration Trends Factsheet 2015. http://publications.iom.int/ books/global-migration-trends-factsheet-2015 Date last accessed: December 22, 2016.

2 United Nations, Department of Economic and Social Affairs, Population Division (2016). International Migration Report 2015: Highlights (ST/ESA/SER.A/375). www.un.org/en/development/desa/population/migration/publications/ migrationreport/docs/MigrationReport2015_Highlights.pdf Date last accessed: December 22, 2016.

3 Klinkenberg E, Manissero D, Semenza JC, et al. Migrant tuberculosis screening in the EU/EEA: yield, coverage and limitations. Eur Respir J 2009; 34: 1180-1189.

4 Aldridge RW, Yates TA, Zenner D, et al. Pre-entry screening programmes for tuberculosis in migrants to low-incidence countries: a systematic review and meta-analysis. Lancet Infect Dis 2014; 14: 1240-1249.

5 de Vries G, van Rest J, Meijer W, et al. Low yield of screening asylum seekers from countries with a tuberculosis incidence of $<50$ per 100000 population. Eur Respir J 2016; 47: 1870-1872.

6 Coker R, Bell A, Pitman R, et al. Tuberculosis screening in migrants in selected European countries shows wide disparities. Eur Respir J 2006; 27: 801-807.

7 Alvarez GG, Gushulak B, Abu Rumman K, et al. A comparative examination of tuberculosis immigration medical screening programs from selected countries with high immigration and low tuberculosis incidence rates. BMC Infect Dis 2011; 11: 3 .

8 Dara M, Solovic I, Goletti D, et al. Preventing and controlling tuberculosis among refugees in Europe: more is needed. Eur Respir J 2016; 48: 272-274.

9 Robert Koch Institute. Report on the Epidemiology of Tuberculosis in Germany 2015 [Berichte zur Epidemiologie der Tuberkulose in Deutschland für 2015]. www.rki.de/DE/Content/InfAZ/T/Tuberkulose/Download/TB2015.pdf? _blob=publicationFile Date last accessed: December 9, 2016.

10 Fiebig L, Hauer B, Brodhun B, et al. Tuberculosis in Germany: a declining trend coming to an end? Eur Respir J 2016; 47: 667-670

11 Protection Against Infection Act [Gesetz zur Verhütung und Bekämpfung von Infektionskrankheiten beim Menschen (Infektionsschutzgesetz - IfSG)]. http://bundesrecht.juris.de/ifsg Date last accessed: December 9, 2016.

12 Robert Koch Institute. Chest X-ray examination among asylum seekers according to Protection Against Infection Act [Thorax-Röntgenuntersuchungen bei Asylsuchenden gemäß $\$ 36$ Absatz 4 IfSG] 2015. www.rki.de/DE/Content/ InfAZ/T/Tuberkulose/Tuberkulose_Roentgen-Untersuchungen_Asylsuchende.html Date last accessed: December 9, 2016.

13 Robert Koch Institute. Tuberculosis diagnostics among asylum seeking children and adolescents $<15$ years of age [Untersuchung auf Tuberkulose bei asylsuchenden Kindern und Jugendlichen < 15 Jahre] www.rki.de/DE/ Content/InfAZ/T/Tuberkulose/Tuberkulose-Screening_Kinder.html Date last accessed: December 22, 2016.

14 TB screening of pregnant women in accordance with the German Protection Against Infection Act. Pneumologie 2016; 70: 777-780.

15 Ritz N, Brinkmann F, Feiterna-Sperling C, et al. Tuberculosis screening for children and adolescents <15 years seeking asylum in Germany. Monatsschrift Kinderheilkunde 2015; 163: 1287-1292.

16 Robert Koch Institute. Case definitions of the Robert Koch Institute for surveillance of notifiable diseases 2015 [Falldefinitionen des RKI zur Übermittlung von Erkrankungs- oder Todesfällen und Nachweisen von Krankheitserregern - Ausgabe 2015]. www.rki.de/falldefinitionen Date last accessed: December 22, 2016.

17 Aldridge RW, Zenner D, White PJ, et al. Tuberculosis in migrants moving from high-incidence to low-incidence countries: a population-based cohort study of 519955 migrants screened before entry to England, Wales, and Northern Ireland. Lancet 2016; 338: 2510-2518.

18 World Health Organization (WHO). Global Tuberculosis Report 2016. http://apps.who.int/iris/bitstream/10665/ 250441/1/9789241565394-eng.pdf?ua=1 Date last accessed: September 272017. 